WIELKIE TEMATY KULTURY W LITERATURACH SŁOWIAŃSKICH

Slavica Wratislaviensia CLXXIII • Wrocław 2021 •AUWr No 3986

https://doi.org/10.19195/0137-1150.173.9

Data przesłania artykułu: 1.09.2019

Data akceptacji artykułu: 1.12.2019

MARINA ROMANENKOVA

Vytautas Magnus University, Kowno, Litwa

\title{
Эксперименты с памятью как способ вхождения в другую культуру (на материале книг Макса Фрая Сказки старого Вильнюса)
}

Сказки старого Вильнюса - общее название серии из семи книг ${ }^{1}$, созданных пишущей на русском языке украинской писательницей Светланой Мартынчик (в соавторстве с мужем) под псевдонимом Макс Фрай с 2012 по 2018 г. Это произведение теснейшим образом связано с новым с 2004 г. для Макса Фрая местом жизни и творчества - Литвой и Вильнюсом. Для того, чтобы рассмотреть заявленную в названии статьи проблему функциональности изображенных в Сказках старого Вильнюса мнемических процессов как элементов культурной идентификации персонажей, необходимо определить, с какой литературной традицией это произведение соотносится. В раскрытии многообразных аспектов взаимообусловленности памяти и Вильнюса ряд современных литературоведов использует понятие „вильнюсский текст” (по аналогии с „петербургским текстом” Владимира Топорова) применительно к различным литературным традициям, с присущей каждой из них своей этнической ментальностью, влияющей на семантику понятия „вильнюсский текст” и функциональность элементов памяти.

1 М. Фрай, Сказки старого Вильнюса I, Санкт-Петербург 2012; М. Фрай, Сказки старого Вильнюса II, Санкт-Петербург 2013; М. Фрай, Сказки старого Вильнюса III, Санкт-Петербург 2014; М. Фрай, Сказки старого Вильнюса IV, Москва 2015; М. Фрай, Сказки старого Вильнюca V, Москва 2016; М. Фрай, Сказки старого Вильнюса VI, Санкт-Петербург 2017; М. Фрай, Сказки старого Вильнюса VII, Москва 2018. В статье используется сокращенное название всей серии Сказки.... Указания на том приводятся римской цифрой, ссылки на страницы - арабской цифрой.

2 „Вильнюсский текст” трактуется исследователями либо как конструкт ментальный, мифопорождающий, либо как собственно текст города (последовательность высказыва- 
С точки зрения концепции семиосферы Юрия Лотмана, формирование феномена ,русского вильнюсского текста” является одним из способов вхождения в другую культуру: „Для того, чтобы общаться с внешней культурой, культура должна интериоризировать ее образ внутрь своего мира"з . „Русский Вильнюс” вошел в русскую культуру путем семиотического пересказа (или перевода в лотмановском смысле) некоего текста с языка одной или нескольких культур - на язык другой. Особенная функция подобного культурного двойника заключается в возможности ,[...] в новом контексте раскрываться совершенно новыми смыслами"4.

В чем исследователям видится уникальность так называемого „русского вильнюсского текста"? Литовский литературовед Павел Лавринец полагает, что суть темы памяти и Вильнюса обусловлена „основной идеей вильнюсского мифа": так называемым „прецедентом” [курсив П. Лавринца. - М. Р.], трактуемым как повторение-возвращение событий и их участников ${ }^{5}$ или как „присвоение Вильнюса”, осуществляемое „благодаря знакам «своей» исторической и культурной традиции, обнаруживаемых в пространстве иной культуры" да на материале русской литературной рецепции Вильнюса XIX-XX в., Лавринец формулирует признаки собственно „русского” восприятия: „Особая черта вильнюсского пространства: прошлое здесь словно и не проходит, оно длится или повторяется. [...] Поэтому редкое произведение о Вильнюсе обходится без памяти, обращенной к собственной биографии или национальному прошлому, т. е. без упоминания прецедента"7. В пользу обоснованности такого подхода к восприятию Вильнюса свидетельствует и обсуждаемая

ний), обусловленный конкретным историческим контекстом. См. напр. П. Лавринец, „Вильнюс” Е. Рейна и „вильнюсский текст” русской поэзии, „Literatūra” 1998, № 38, с. 103-112; В. Брио, Поэзия и поэтика города: Wilno-Bилнэ-Vilnius, „Новое литературное обозрение”, Москва 2008; P. Lavrinecas, Rusiškas Vilniaus tekstas, [в:] Naujasis Vilniaus perskaitymas: didieji Lietuvos istoriniai pasakojimai ir daugiakultūrinis miesto paveldas, ред. А. Bumblauskas, Š. Liekis, G. Potašenko, Vilniaus universiteto leidykla, Vilnius 2009, с. 3-22; И. Видугирите, Петербургский текст русской литературы и Вильнюсский текст литовской литературы: ещее раз об аналитическом потенциале концепции В. Н. Топорова, „Literatūra” 2013, № 55, с. 7-16; Т. Венцлова, К сопоставлению вильнюсского и таллиннского текста, [в:] Семиотика города. Материальь Третьих Лотмановских дней в Таллиннском университете (3-5 июня 2011), ред. И. А. Пильщиков, Таллинн 2014, с. 29-55; И. Видугирите, Вильнюс: текст города и город текста, [в:] Семиотика города..., с. 100-117; П. Лавринец, Вильнюс как „другое пространство” в русской литературе, [в] Heterotopijos: pasauliai, ribos, pasakojimai, ред. G. Michailova, I. Vidugiryte, P. Lavrinec, Vilnius 2015, c. 274-284.

3 Ю. М. Лотман, К построению теории взаимодействия культур, [в:] idem, Семиосфера, Санкт-Петербург 2001, с. 610.

4 Ibidem, c. 613.

5 P. Lavrinecas, Rusiškas Vilniaus tekstas..., c. 11.

6 П. М. Лавринец, Присвоение Вильнюса в русской литературе, „Уральский исторический вестник” 2014, № 3, с. 67-68.

7 P. Lavrinecas, Rusiškas Vilniaus tekstas..., c. 20.

Slavica Wratislaviensia 173, 2020

(C) for this edition by CNS 
в исторических штудиях так называемая концепция „ментальных карт” русского националистического проекта XIX века ${ }^{8}$. Функция элементов памяти в русском вильнюсском тексте связана и с особого рода формой личного воспоминания.

Вышедшие первые две книги серии Сказок... Лавринец относит к традиции русского вильнюсского текста условно: по параметру восприятия Вильнюса как „другого”, гетеротопического, пространства (сюжеты о событиях чудесных, фантастических $)^{9}$, проницательно уловив необходимость иного подхода к этому произведению.

Для Мартынчик решение переехать в другую страну и заниматься творчеством было добровольным выбором ${ }^{10}$ в поиске приемлемых с ее точки зрения социальных отношений в изменившемся контексте межкультурных коммуникаций. По словам литовского исследователя Таисии Лаукконен, „для обозначения этой новой ситуации возникает термин „постдиаспора” 11 . Подобный процесс сопровождается и закономерным кризисом идентичности, что в случае Макса Фрая, признающего существование понятия и масштабного явления „русскоязычный писатель” ${ }^{\prime 2}$, выразилось в открытом отмежевании от российского литературного процесса ${ }^{13}$.

${ }^{8}$ См. подробнее: А. Миллер, Империя Романовых и национализм: Эссе по методологии исторического исследования (гл. Империя и начия в воображсении русского национализма), Москва 2008, с. 147-170. Как показал Миллер, Россия, подобно другим континентальным империям, осуществляла свой „русский националистический проект консолидации нации внутри империи, который предполагал „присвоение” определенной части имперского пространства как „русской национальной территории”. Автор пишет „о сложном комплексе дискурсивных практик, который включал в себя идеологическое обоснование, символическое, топонимическое, художественное освоение определенного пространства таким образом, чтобы общественное сознание осмысливало это пространство как часть именно „своей”, „национальной” территории” (А. Миллер, Империя и нащия..., с. 156). Думается, что художественная стратегия „присвоения” Вильнюса как одна из ведущих культурных тенденций коррелирует с имперскими по духу (в том числе советскими) „ментальными картами”. О механизме создания мифа „французской имперскости” см. Р. Барт, Мифологии, пер. С. Зенкина, Москва 2010, с. 267-291.

9 П. Лавринец, Вильнюс как ,, другое пространство” в русской литературе ..., с. 279-280.

10 См. интервью: К. Амелюшкин, Макс Фрай: литература - это не спорт, ru.DELFI. 1t, 31 марта 2010 г., https://ru.delfi.lt/misc/culture/maks-fraj-literatura-eto-ne-sport.d?id=30598571 [доступ: 20.06.2019]. С. Мартынчик с мужем являются гражданами Украины. См. С. Сдобнов, Макс Фрай: „После Майдана сообщать о своем украинском гражданстве мне стало приятно”, https://www.colta.ru/articles/literature/7074 [доступ: 20.06.2019].

11 Т. Лаукконен, Гетеротопии национального поля литературы: теоретические проблемы исследования ,„ругих литератур” Литвы, [в:] Heterotopijos..., с. 247.

12 К. Амелюшкин, Макс Фрай: литература - это не спорт...

13 В интервью Макс Фрай пояснила: „Я с 2004 года живу в Вильнюсе и совершенно не представляю, что творится в этом самом литературном мире. [...] Тот факт, что я пишу по-русски, не накладывает на меня обязательства интересоваться литпроцессом на русском языке [...]”. См. И. Ватолин, „Если завтра запретят интернет или разрешат гей-браки”. Макс Фрай и Илья Данишевский о том, как ничему не удивляться, „Спектр” 03.03.2017, http:// 
В сфере дискурса постсоветского диаспорического субъекта Лаукконен выделяет тенденцию формирования новых локальных идентичностей, литературных и авторских, в изучении которых, тем не менее, роль феномена Вильнюса как культурного образца, „основного топоса” 14 , неизменна. Как для самой Мартынчик в ее новом статусе постдиаспорического субъекта, так и для многих героев Сказок..., меняются мотивация и цель появления в Вильнюсе: они собираются в этом месте жить вопреки различным ограничительным идеям (гражданства, культурно-исторического и этнического своеобразия чужой страны и т. д.), что придает их целеполаганию даже экзистенциальный смысл:

[...] завладей семью вещами, на которые не имеешь права по рождению. [...] Можно просто уехать из города, в котором ты родился, поселиться в другом, изучить его лучше, чем старожилы, полюбить, устроиться, завести дом, [...] словом, сделать чужой город своим [...] (VII, 152). Я приехал в Вильнюс потому [...], что хотел начать новую жизнь. Такую, как всегда хотелось. [...] не туристом [...] проскакать, а пожить по-настоящему [...], что-то начать понимать [...] (III, 214).

В создании локальной идентичности, свободно конструируемой как идентификация с новым местом проживания, Макс Фрай как „русскоязычный писатель", думается, как-то иначе причастен к русской литературной традиции, и когда мы обращаемся к интерпретации темы памяти в тексте Сказок, то можно предположить, что в его смысловой модели Вильнюса будет присутствовать по-новому осмысленный эффект прецедента. В чем же заключается художественное решение Фрая?

Проблема авторского смысла в Сказках... передоверена Мартынчик Максу Фраю, ироничному повествователю и одному из нескольких вильнюсских „гениев места”, задающему программу чтения текста:

Здесь иначе вообще нельзя. [...] открываем все окна и двери нараспашку, выворачиваем наизнанку все, что получится вывернуть, стираем границы между явью и сном, перемешиваем сбывшееся с несбывшимся, в самых неожиданных местах размещаем удивительные возможности, а сверху густо посыпаем прельстительными наваждениями, просто для красоты [...] (VII, 16-17).

В соответствии с этим псевдосказочным кодом и специализированные проблемы культуры и науки, связанные с концепциями памяти (в частности, Анри Бергсона), актуализируются и „освежаются” в ироническом пересказе мнимо простодушных гениев места, ответственных за эксперименты с памятью обывателей и приезжих:

Но, слушай, прошлое - это такая скользкая тема. Вроде было, а вроде и не было, веры ему, сам знаешь, нет, а памяти - тем более, особенно нашей с тобой. Через какое плечо обернешься назад, то и увидишь, и никаких гарантий, что новое воспомина-

spektr.press/esli-zavtra-zapretyat-internet-ili-razreshat-gej-braki-maks-fraj-i-ilya-danishevskij-otom-kak-nichemu-ne-udivlyatsya/ [доступ: 25.06.2019].

14 Т. Лаукконен, Гетеротопии..., с. 251.

Slavica Wratislaviensia 173, 2020

(C) for this edition by CNS 
ние хоть когда-то было правдой. Прошлое - зыбкая топь, наваждение, которое длится и длится, овеществляясь в каждом нашем вдохе и выдохе, вот прямо сейчас (Ул. Исландийос, /Islandijos g./, За черной-черной стеной, III, 167-168).

$[\ldots]$ машину времени так и не изобрели, прошлого, как известно, вовсе нет, и будущего тоже, есть только слова „прошлое”, „будущее”, помогающие заполошному человеческому уму хоть как-то принять и освоить бесконечное переменчивое „сейчас” ( $У_{л}$. Швенто Миколо /Švento Mykolo g./ Покупки поздно вечером, III, 460).

Более того, гении места могут „переписывать прошлое или хотя бы то, что мы помним о нем [...] Не понравится, перепишем заново, что-то вычеркнем, досочиним [...], будем переделывать снова и снова, пока все не станет таким, как угодно нам " (III, 167-168). Авторский смысл в Сказках... стремится реализоваться как бы „вопреки здравому смыслу” (V, 119).

Образ Вильнюса, с которым идентифицируются „гении места” и персонажи Сказок..., базируется на исторической легенде об онейрических „истоках" Вильнюса (князю Гедиминасу приснился сон: на высокой горе выл железный волк, что было истолковано жрецами как указание на место новой столицы Великого Княжества Литовского) и представляет собой постмодернистский инвариант окказиональной картины мира, допускающего со стороны сознания различные способы понимания своей предметности ${ }^{15}$.

Говорят, человек часто видит не то, что на самом деле показывают, а то, что заранее ожидает увидеть, мозг так устроен, сейчас много об этом пишут, вон даже до меня донеслось, хотя я не особенно интересуюсь всеми этими популярными открытиями в области устройства сознания $(\mathrm{V}, 57)$.

Вильнюс, как как утверждает Макс Фрай в Сказках..., - это по сю пору длящийся сон Гедиминаса. В этом решении Макса Фрая видится необходимость акцентировать в топосе Вильнюса новейшие элементы идентичности: открытое и свободное смешение и взаимопроникновение своих и чужих ценностных установок и культурных образцов ${ }^{16}$. Персонажи Сказок... переживают процесс мнемического распознавания Вильнюса во сне, подобно сну Гедиминаса о городе, и, если можно так выразиться, подключаясь и к сновидениям друг друга, и к сновидениям, „общим для Старого города” (V, 17), как бы сливаются с Вильнюсом во сне. Вильнюс в Сказках... изоморфен легендарному сну, и наилучший способ идентифицироваться с Вильнюсом, формально сохраняющим топографию старого города, - встроиться, вписаться в исторический миф: „Просто наш город, так вышло, был построен на фундаменте сновидения. Общеизвестная легенда об уснувшем князе [...]

15 В. И. Тюпа, Дискурсные формачии: Очерки по компаративной риторике, Москва 2010, c. 114.

16 Т. В. Шарнаускене, Идентичность и прецедент в модернизационных процессах, „Знание. Понимание. Умение” 2010, № 2, с. 94-99, https://cyberleninka.ru/article/n/identichnosti-pretsedent-v-modernizatsionnyh-protsessah [доступ: 29.07.2019]. 
позволяет не забывать об истинной природе этого места" (V, 392-393). Гении места много раз разъясняют это обстоятельство:

Штука в том, что наш город — наваждение [...] Но такое лукавство, конечно, совершенно не мешает городу оставаться живым, текучим и переменчивым, как и положено всякому нормальному наваждению. Достоверность - наиважнейшая часть затеянной им игры (IV, 154).

Вильнюс у Фрая семиотизируется в соответствии с легендарно-мифологическим „фундаментом”: в Сказках... сосуществуют два города, и в качестве условного прецедента выступает фрайевский мифообраз Вильнюса город-сон:

Вильнюс - пограничный город [...], у города есть близнец, тайная тень, близкая, совершенно недостижимая и в то же время явственно присутствующая - всюду, и прямо здесь тоже, прямо сейчас и всегда $[\ldots]$; без тени нашему городу не обойтись, тогда в нем не останется ни жизни, ни смысла (V, 230-231).

Опираясь на рассуждениях Ролана Барта о мифе, можно интерпретировать образ города-сна как „совокупный знак”, включающийся в структуру мифа ${ }^{17}$, в данном случае - исторического. Город-сон получает статус метаязыка, которым описывается означаемое мифа, или понятийная интенция, подкрепляющая обоснованный смысл чувствовать себя в чужом городе так, „словно вернулся домой” (VII, 130). В презентации Вильнюса с проходящей по нему „границей между мирами, реальностями, вероятностями” $(\mathrm{V}, 230-231)$ комбинация мотивов памяти и сна выполняет основную сюжетообразующую функцию ${ }^{18}$, хотя надо признать, что элементы памяти играют в них вспомогательную роль. Находящиеся в прецедентном Вильнюсе герои силою своих сновидений и памяти способны перестраивать реальный город ${ }^{19}$ : в нем появляются новые улицы и достопримечательности. Мнемиче-

17 Р. Барт, Мифологии..., с. 272.

18 См., например: Улииа Басанавичяус J. Basanavičiaus g.) Шесть комнат, I; Улииа Бернардину (Bernardinu g.) Какие сны, I; Улиия Лапу (Lapu g.) Много прекрасныхх дорог, I; Улиияа Жигиманту (Žygimantu g.) Сто рыб, II; Улица Одминю (Odminiu g.) Сто сорок девять дворов, II; Улии Палангос (Palangos g.) Например, позавчера, II; Улица Кедайню (Kedainiu g.) Требуется чудовище, V; Переулок Крейвасис (Kreivasis skg.) Темнее, чем просто тьма, V; Улиияа Pacy (Rasu g.) А вы как хотите, V; Улица Швентараге (Šventaragio g.) Строительный материал, V; Улица Лейиклос (Liejyklos g.) Площадь Восьмидесяти Тоскующих Мостов, V; Улииа Кауно (Kaипо g.) Где-то здесь рядом, VI; Рынок Тимо (Tуто Turgus) Субботник, VI; Площадь Йоно Жемайчё (Јопо Žетаіс̌іо а.) Правила джиннов, VII и др.

19 Из рассказа Улииа Швенто Казимеро (Ц̌v. Kazimiero g.) И вот тут я теперь живу: „Он [Вильнюс. - М. Р.] же только притворяется обычным городом, похожим на множество других, а на самом деле, такой же как я, удачно замаскированный пришелец, чужак на этой земле, призрачное подобие, текучий мираж, чьи очертания постоянно изменяются одновременно с памятью горожан, так что каждое утро они выходят на обновленные улицы в полной уверенности, что всегда так и было [...]” (IV, 462). Из рассказа Сквер Лаздину Пеледос (Lazgynu Peledos skveras) Хана: „В этом городе я в каком-то смысле всегда стою перед зеркалом, куда ни повернусь, везде вижу себя [...] как же я все это люблю" (VI, 172).

Slavica Wratislaviensia 173, 2020

(C) for this edition by CNS 
ские процессы неотчетливого, смутного знания и распознавания, придумывания и припоминания - второго города как истинного, как дома - участвуют в формировании семантики сюжета „возвращение домой”:

Почти каждому, кто заходит в этот двор, мерещится, будто он уже жил здесь прежде. Даже тому, кто впервые прибыл в Вильнюс утром текущего дня, вдруг начинает казаться, что вон за той деревянной дверью без номера — дом его детства [...] Люди обычно тяжело переносят подобные конфликты памяти и здравого смысла. Поэтому подавляющее большинство поспешно уходит отсюда в смятении, но некоторые любопытные смельчаки все же решаются задержаться и даже постучать в бывшую свою дверь. Им всегда отпирают, а дальше - по обстоятельствам [...] (II, 125).

Итак, рассмотренные эксперименты гениев места с памятью персонажей являются особенностью поэтики Сказок старого Вильнюса, их функциональность и семантика отражают ментальность современной эпохи модернизации. Содержание модели вильнюсского „прецедента”, предложенной Лавринцом, в определенной степени было обусловлено „имперскими” ментальными представлениями и окрашено личным восприятием „своего” в „чужом”. В окказиональном мифе Вильнюса-сна у Макса Фрая акцентируется семантика утешения, обретения дома, что оказалось релевантным содержанию легендарного сна Гедиминаса об основании города (в том числе и как места проживания). Подвижный, меняющийся образ Вильнюса базируется на другой комбинации знаков: „чужое” осваивается, интегрируется как „свое”. Цепочка повторяющихся мнемических реакций, связанная с распознаванием примет своего дома в прецедентном городе-тени, гарантирует персонажам „онейрическую” вильнюсскую идентичность с коннотацией проницаемости всякого рода границ. Семантика стереотипной схемы сюжета варьируется на протяжении всей серии книг, что позволяет интерпретировать Сказки... как перекодировку личного благополучного эмигрантского опыта Мартынчик и ее вхождения в чужую культуру. Как справедливо пишет Ролан Барт, „целая книга может оказаться означающим одного-единственного понятия" 20 .

\section{Библиография}

Amelûškin K., Maks Fraj: literatura - èto ne sport, «ru.DELFI.lt», 31 marta 2010 g, https://ru.delfi.lt $/ \mathrm{misc} /$ culture/maks-fraj-literatura-eto-ne-sport.d?id=30598571.

Bart R., Mifologii, Akad. Proekt. Fr. Proekt, Moskva 2010.

Brio V., Poèzija i poètika goroda: Witno-Vilnè-Vilnius, Novoe literaturnoe obozrenie, Moskva 2008.

Fraj M., Skazki starogo Vil'nûsa I, Amfora, Sankt-Peterburg 2012.

Fraj M., Skazki starogo Vil'nûsa II, Amfora, Sankt-Peterburg 2013.

Fraj M., Skazki starogo Vil'nûsa III, Amfora, Sankt-Peterburg 2014.

Fraj M., Skazki starogo Vil'nûsa IV, AST, Moskva 2015.

Fraj M., Skazki starogo Vil'nûsa V, AST, Moskva 2016.

Fraj M., Skazki starogo Vil'nûsa VI, AST, Sankt-Peterburg 2017.

20 Р. Барт, Мифологии..., с. 278.

Slavica Wratislaviensia 173, 2020

(C) for this edition by CNS 
Fraj M., Skazki starogo Vil'nûsa VII, AST, Moskva 2018.

Laukkonen T., Geterotopii nacional'nogo polâ literatury: teoretičeskie problemy issledovaniâ ,,drugih literatur" Litvy, [v:] Heterotopijos: pasauliai, ribos, pasakojimai, red. G. Michailova, I. Vidugiryte, P. Lavrinec, Izdatel'stvo vil'nûsskogo universiteta, Vilnius 2015.

Lavrinec P. M., Prisvoenie Vil'nûsa v russkoj literature, „Ural'skij istoričeskij vestnik” 2014, № 3.

Lavrinec P. M., „Vil'nûs” E. Rejna i ,vil'nûsskij tekst” russkoj poèzii, „Literatūra” 1998, № 38.

Lavrinec P. M., Vil'nûs kak ,drugoe prostranstvo" v russkoj literature, [v:] Heterotopijos: pasauliai, ribos, pasakojimai, red. G. Michailova, I. Vidugirytė, P. Lavrinec, Izdatel'stvo vil'nûsskogo universiteta, Vilnius 2015.

Lavrinecas P., Rusiškas Vilniaus tekstas, [v:] Naujasis Vilniaus perskaitymas: didieji Lietuvos istoriniai pasakojimai ir daugiakultūrinis miesto paveldas, red. A. Bumblauskas, Š. Liekis, G. Potašenko, Vilniaus universiteto leidykla, Vilnius 2009.

Lotman J. M., K postroeniû teorii vzaimodejstviâ kul'tur, [v:] idem, Semiosfera, Iskusstvo-SPB, Sankt-Peterburg 2001.

Miller A., Imperiâ Romanovyh i nacionalizm: Èsse po metodologii istoričeskogo issledovaniâ, Novoe literaturnoe obozrenie, Moskva 2008.

Sdobnov S., Maks Fraj: „Posle Majdana soobŝat' o svoem ukrainskom graždanstve mne stalo priâtno", https://www.colta.ru/articles/literature/7074.

Šarnauskene T. V., Identičnost' i precedent v modernizacionnyh processah, „Znanie. Ponimanie. Umenie” 2010, № 2, https://cyberleninka.ru/article/n/identichnost-i-pretsedent-v-modernizatsionnyhprotsessah.

Tûpa V. I., Diskursnye formacii: Očerki po komparativnoj ritorike, Âzyki slavânskoj kul'tury, Moskva 2010.

Vatolin I., „Esli zavtra zapretât internet ili razrešat gej-braki”. Maks Fraj i Il'â Daniševskij o tom, kak ničemu ne udivlat'sâ, „Spektr” 3.03.2017, http://spektr.press/esli-zavtra-zapretyat-internet-ili-razreshat-gej-braki-maks-fraj-i-ilya-danishevskij-o-tom-kak-nichemu-ne-udivlyatsya.

Venclova T., K sopostavleniû vil'nûsskogo i tallinnskogo teksta, [v:] Semiotika goroda. Materialy Tret'ih Lotmanovskih dnej v Tallinnskom universitete (3-5 iûnâ 2011), red. I. A. Pil'ŝikov, Izdatel'stvo TLU, Tallinn 2014.

Vidugirite I., Peterburgskij tekst russkoj literatury $i$ Vil'nûsskij tekst litovskoj literatury: eŝe raz ob analitičeskom potenciale koncepcii V. N. Toporova, „Literatūra” 2013, № 55.

Vidugirite I., Vil'nûs: tekst goroda i gorod teksta, [v:] Semiotika goroda. Materialy Tret'ih Lotmanovskih dnej v Tallinnskom universitete (3-5 ijûnâ 2011), red. I. A. Pil'ŝikov, Izdatel'stvo TLU, Tallinn 2014

\section{Experiments with Memory as a Key to Acquisition of a Foreign Culture (on the Material of Max Frei's Books Skazki starogo Vilniusa [The Tales of Old Vilnius])}

\section{Summary}

The article aims to consider the functionality of memory elements as a means of identifying characters who - at their own will - change their location of residence and find themselves in a different cultural environment. Max Frei's appropriation of Vilnius is based on the experience of the "dreamer" character. His state is likened to that of Prince Gediminas's, who saw the future city in his dream while he was sleeping. Max Frei completes the myth-dream of Vilnius with the mnemic processes of obscure recollecting, vague recognition. These have a relation to the sub- 
liminal wish of the characters to have Vilnius as their home. The semiotic approach to the analysis of memory elements in the aspect of identity allowed to reveal the connection of The Tales of Old Vilnius with Max Frei's personal experience of emigration and to identify new elements in the creation of the author's local identity.

\section{Eksperymenty z pamięcią jako sposób oswojenia nowej kultury (na przykładzie książek Maksa Fraja Сказки старого Вильнюса [Bajki starego Wilna])}

\section{Streszczenie}

W artykule poddano analizie funkcje elementów pamięci jako składowych tożsamości postaci, które z własnej woli zmieniają miejsce zamieszkania i znajdują się w obcym kręgu kulturowym. W oswojeniu Wilna przez Maksa Fraja ważne miejsce zajmuje doświadczenie śniącego bohatera, upodobnionego do mitologicznego onirycznego księcia Giedymina, któremu przyśniło się przyszłe miasto. Fraj wpisuje do wileńskiego mitu - marzenia sennego mnemiczne procesy mglistego wspominania, niewyraźnego rozpoznawania, co wiąże się z podświadomym pragnieniem bohaterów, by znaleźć w Wilnie swój dom. Semiotyczna analiza elementów pamięci w aspekcie tożsamości pozwala na zestawienie zbioru Сказки старого Вильнюса z emigracyjnym doświadczeniem samego autora oraz na ujawnienie nowych elementów formowania się jego lokalnej tożsamości.

Stowa kluczowe: Maks Fraj, pamięć, Bajki starego Wilna, tożsamośc lokalna 